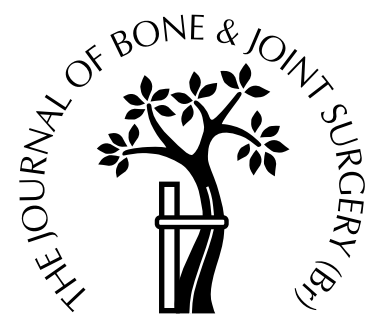

\title{
Anatomical reconstruction and Evans tenodesis of the lateral ligaments of the ankle
}

\author{
CLINICAL AND RADIOLOGICAL FINDINGS AFTER FOLLOW-UP \\ FOR 15 TO 30 YEARS
}

\author{
R. Krips, S. Brandsson, C. Swensson, C. N. van Dijk, J. Karlsson \\ From the Sahlgrenska University Hospital, Göteborg, Sweden
}

$I^{\mathrm{n}}$ this retrospective study, we assessed the outcome in 99 patients who underwent reconstruction of the lateral ligaments of the ankle for chronic anterolateral instability with a minimum follow-up of 15 years.

Two techniques were compared: 54 patients had an anatomical reconstruction (AR group) and 45 had an Evans tenodesis (ET group). They were followed up for $19.9 \pm 3.6$ years and $21.8 \pm 4.6$ years, respectively. During follow-up, seven patients in the AR group and 17 in the ET group required a further operation ( $p=0.004$ ). At follow-up, significantly more patients $(n=15)$ in the ET group had limited dorsiflexion than in the AR group $(n=6, p=0.007)$ and 18 in the ET group had a positive anterior drawer test compared with seven in the AR group $(p=0002)$. In the ET group 27 had tenderness on palpation of the ankle compared with 15 in the $A R$ group $(p=0.001)$. Stress radiographs showed ligamentous laxity significantly more often in the ET group $(n=30)$ than in the AR group $(n=13, p<0.001)$. The mean values for talar tilt and anterior talar translation were significantly higher in the ET group than in the AR group $(p<0.001$, $\mathbf{p}=\mathbf{0 . 0 0 7}$, respectively). There were degenerative changes on standard radiographs in 32 patients in the AR group and 35 in the ET group $(p=0.05)$. Four patients in the ET group had developed severe osteoarthritis compared with none in the AR group $(p=0.025)$. Assessment of functional stability revealed a mean Karlsson score of $83.7 \pm 10.4$ points in the $A R$ group and $67.0 \pm 15.8$ points in the ET group (p< 0.001). According to the Good rating system, 43 patients in the AR group had good or excellent results compared with 15 in the ET group $(p<0.001)$.

R. Krips, MD

C. N. van Dijk, MD, PhD

Department of Orthopaedic Surgery, Academic Medical Centre, Meibergdreef 9, Postbus 226601100 DD Amsterdam, The Netherlands.

S. Brandsson, MD, PhD

C. Swensson, MD

J. Karlsson, $\mathrm{MD}, \mathrm{PhD}$, Professor

Department of Orthopaedics, Sahlgrenska University Hospital, SE-416 85 Göteborg, Sweden.

Correspondence should be sent to Professor J. Karlsson.

(C2002 British Editorial Society of Bone and Joint Surgery 0301-620X/02/212143\$2.00
Compared with anatomical reconstruction, the Evans tenodesis does not prevent laxity in a large number of patients. Long-standing ligamentous laxity leads to degenerative change in the ankle, resulting in chronic pain, limited dorsiflexion and further operations. The functional result deteriorates more rapidly after the Evans tenodesis than after anatomical reconstruction.

J Bone Joint Surg [Br] 2002;84-B:232-6.

Received 1 February 2001; Accepted after revision 30 May 2001

Chronic anterolateral instability of the ankle can be treated effectively by repair of the lateral ligaments. Tenodesis or reconstruction using an autogenous tendon graft, however, has been used in most studies. ${ }^{1-20}$ This usually involves a tenodesis between the distal fibula and the calcaneus, the talus or the base of the fifth metatarsal. The Evans procedure is a widely used non-anatomical reconstruction. ${ }^{21}$ It was originally described in 1953. Several subsequent modifications have been utilised. ${ }^{4}$ While the short-term results are satisfactory in most patients, it has been suggested that the results of tenodesis deteriorate with time. ${ }^{18,22}$ Karlsson et $\mathrm{al}^{22}$ reported that approximately $50 \%$ of patients had a poor result ten to 17 years after an Evans procedure, whereas Sugimoto et $\mathrm{al}^{23}$ reported satisfactory results in $90 \%$ of patients ten to 18 years after a Watson-Jones tenodesis. Anatomical reconstruction has a more consistent outcome, with satisfactory results in $80 \%$ to $90 \%$ of cases. ${ }^{24-26}$ To our knowledge, the long-term results of anatomical reconstruction with a follow-up of more than ten years have not been reported. A multicentre comparison between anatomical reconstruction and tenodesis has recently been presented by Krips et al. ${ }^{27}$ This showed better results for the former procedure with regard to function of the ankle, stability, laxity and degenerative changes two to ten years after operation. We sought to compare the long-term outcome of these two techniques at more than 15 years.

\section{Patients and Methods}

Between 1970 and 1985 we treated 112 patients with chronic anterolateral instability of the ankle using either anatomical reconstruction or the Evans tenodesis. Four 
different surgeons were involved. All patients had had symptoms for at least six months and had received physiotherapy before surgery. The decision as to which procedure was performed was made by the surgeon who undertook it. The criteria for inclusion in the study included age at operation between 16 and 40 years, a normal contralateral ankle, no previous history of fracture of the ankle, no previous surgery other than an anatomical reconstruction or a tenodesis and no history of joint hypermobility, generalised neuromuscular disorder or subtalar instability.

Of the 112 patients 59 had an anatomical reconstruction and 53 a tenodesis. Thirteen were lost to follow-up leaving 99 in the study. Of these, 54 had an anatomical reconstruction (AR) and 45 a tenodesis (ET). There were no significant differences in the baseline characteristics between the patients included in the study and those lost to follow-up.

All patients in the AR group had an anatomical reconstruction, as described by Karlsson et al. ${ }^{25}$ In the ET group, all had a routine Evans tenodesis. ${ }^{4}$ Postoperatively, all were immobilised in a plaster-of-Paris cast for six weeks before starting physiotherapy.

The mean age of the patients in the AR group was $25 \pm$ 4.2 years and in the ET group $24 \pm 4.2$ years. The male: female ratio was 32:22 in the AR group and 30:15 in the ET group. The left: right ratio was 28:26 in the AR group and 18:27 in the ET group. The mean follow-up was $19.9 \pm 3.6$ years in the AR group and $21.8 \pm 4.6$ years in the ET group.

At review details of postoperative complications, revision procedures and further injuries were noted. The functional outcome was assessed using the Karlsson score and the rating system described by Good et al. ${ }^{6,28}$ Absence of symptoms was considered to be an excellent result. Dorsiand plantar flexion were measured to the nearest $5^{\circ}$ using a goniometer. A reduction of more than $5^{\circ}$ in comparison with the contralateral ankle was considered to represent a limited range. Swelling and tenderness were recorded, and ligamentous laxity was tested using the anterior drawer test with the ankle in $15^{\circ}$ of plantar flexion. This test was considered to be positive if there was a difference of more than $5 \mathrm{~mm}$ compared with the contralateral ankle. Radiological examination included anteroposterior, lateral and stress radiographs of both ankles. Talar tilt and anterior talar translation were assessed according to the criteria established by Lindstrand and Mortensson. ${ }^{29}$ A standard load of $150 \mathrm{~N}$ was applied, using Telos apparatus (Forsta, Schenba and Weber, Hamburg, Germany). ${ }^{28}$ Talar tilt was regarded as positive if the tibiotalar angle was more than $10^{\circ}$ or when the difference between ankles was more than $6^{\circ}$. Anterior talar translation was regarded as positive when the anterior displacement of the talus relative to the tibia was more than $4 \mathrm{~mm}$ or the difference between the ankles was more than $3 \mathrm{~mm} .{ }^{30}$ Degenerative changes were graded according to the scale developed by van Dijk et al. ${ }^{30}$ All radiographs were assessed by an independent observer (RK).
Statistical analysis. We analysed differences in baseline characteristics and final results between the different surgeons and operations. The comparison of mean values for anatomical reconstructions and tenodeses was calculated using analysis of variance (ANOVA). The comparison of proportions was calculated using the chi-squared test. A p value of $<0.05$ was considered to be statistically significant.

\section{Results}

Table I gives the details of the results.

Postoperative complications. One patient in the AR group and three in the ET group had a wound infection. One patient in the ET group had a deep-venous thrombosis. In the AR group, 11 patients had altered cutaneous sensation compared with 16 in the ET group. The number of postoperative complications did not differ significantly between the two groups $(\mathrm{p}=0.091)$.

Reoperations. Seven patients in the AR group had a revision procedure. Three had arthroscopy to remove anterior tibial spurs, two had scar tissue removed, one had a revision of an anatomical reconstruction and one sustained an injury to the tibialis posterior tendon and underwent reconstruction. In the ET group, 17 ankles had a revision procedure. Nine had arthroscopy for anterior bony impingement with removal of osteophytes, three had reefing of the capsule because of persistent laxity, three had a partial synovectomy for anterior soft-tissue impingement and pain and two had exploration of a neuroma. One patient had a revision procedure for rupture of the peroneus brevis tendon. The number of patients who had a revision procedure was significantly higher in the ET group $(p=0.004)$.

Subjective. According to the scale developed by Karlsson et $\mathrm{al}^{28}$ ten patients in the AR group had an excellent functional outcome (91 to 100 points) compared with four in the ET group $(\mathrm{p}=0.171)$. There were significantly more patients with a good result (81 to 90 points) in the AR group $(n=29)$ than in the ET group $(n=4, p<0.001)$. The number of patients with a fair result (61 to 80 points) was significantly higher in the ET group $(n=21)$ than in the AR group $(n=13, p=0.018)$ and there were significantly more patients with a poor result ( $<60$ points) in the ET group $(\mathrm{n}=16)$ than in the AR group $(\mathrm{n}=2, \mathrm{p}<0.001)$. The mean Karlsson score was $83.7 \pm 10.4$ points in the AR group and $67.0 \pm 15.8$ in the ET group $(\mathrm{p}<0.001)$.

With regard to the Good scale, there were significantly more patients with a good result in the AR group than in the ET group (29 $v$ 9, $\mathrm{p}=0.001)$. Furthermore, there were significantly more patients with a fair outcome $(p=0.001)$ and with a poor outcome $(\mathrm{p}=0.001)$ in the ET group $(20$ fair, 10 poor) than in the AR group (10 fair, 1 poor). An excellent result was obtained in 14 patients in the AR group and 6 in the ET group $(\mathrm{p}=0.120)$.

Objective. Significantly more patients $(n=15)$ in the ET group had limited dorsiflexion than in the AR group $(n=6$, 
Table I. Details of the results in the 54 patients with AR and 45 with ET

\begin{tabular}{|c|c|c|c|}
\hline & $\mathbf{A R}$ & ET & p value \\
\hline Postoperative complications & 1 & 4 & 0.091 \\
\hline Reoperations & 7 & 17 & 0.004 \\
\hline Restricted ROM & 6 & 15 & 0.007 \\
\hline Tenderness & 15 & 27 & 0.001 \\
\hline Swelling & 8 & 8 & 0.690 \\
\hline Anterior drawer sign & 7 & 18 & 0.002 \\
\hline Mean $( \pm \mathrm{SD})$ Karlsson $^{2}$ score (points) & $83.7 \pm 10.4$ & $67.0 \pm 15.8$ & $<0.001$ \\
\hline Excellent (91 to 100$)$ & 10 & 4 & 0.171 \\
\hline Good (81 to 90$)$ & 29 & 4 & $<0.001$ \\
\hline Fair (61 to 80$)$ & 13 & 21 & 0.018 \\
\hline Poor $(<60)$ & 2 & 16 & $<0.001$ \\
\hline \multicolumn{4}{|l|}{ Good $^{4}$ score (grade) } \\
\hline Excellent & 14 & 6 & 0.120 \\
\hline Good & 29 & 9 & 0.001 \\
\hline Fair & 10 & 20 & 0.001 \\
\hline Poor & 1 & 10 & 0.001 \\
\hline
\end{tabular}

Table II. Results of stress radiological examination in the 54 patients who received anatomical reconstruction (AR group) and the 45 who had the Evans tenodesis (ET) for chronic anterolateral instability of the ankle

\begin{tabular}{llll}
\hline & AR $(\mathbf{n}=\mathbf{5 4})$ & $\mathbf{E T}(\mathbf{n}=\mathbf{4 5})$ & $\mathbf{p}$ value \\
\hline Mean $( \pm$ SD) talar tilt in degrees & & & \\
$\quad$ Affected ankle & $3.3 \pm 3.8$ & $7.9 \pm 5.9$ & $<0.001$ \\
$\quad$ Unaffected ankle & $3.2 \pm 3.8$ & $5.1 \pm 4.4$ & 0.024 \\
$\quad$ Difference & $0.13 \pm 3.4$ & $2.9 \pm 5.5$ & 0.003 \\
Mean $( \pm$ SD) anterior talar translation $(\mathrm{mm})$ & & \\
$\quad$ Affected ankle & $3.6 \pm 2.1$ & $5.0 \pm 3.1$ & 0.007 \\
Unaffected ankle & $3.5 \pm 2.1$ & $3.1 \pm 2.2$ & 0.444 \\
Difference & $0.083 \pm 2.3$ & $1.8 \pm 3.6$ & 0.004 \\
\hline
\end{tabular}

$\mathrm{p}=0.007$ ). Seven patients in the AR group had a positive anterior-drawer test compared with 18 in the ET group $(p=0.002)$. Tenderness of the ankle was reported by 15 patients in the AR group and 27 in the ET group $(p=0.001)$. Eight patients in both groups had swelling of the ankle $(\mathrm{p}=0.690)$.

Radiological. On stress radiographs the mean talar tilt was $3.3 \pm 3.8^{\circ}$ in the AR group and $7.9 \pm 5.9^{\circ}$ in the ET group $(\mathrm{p}<0.001)$. As shown in Table II, the mean anterior talar translation was $3.6 \pm 2.1 \mathrm{~mm}$ in the AR group compared with $5.0 \pm 3.1 \mathrm{~mm}$ in the ET group $(\mathrm{p}=0.007)$. The number of patients with degenerative changes on standard AP and lateral radiographs was 32 in the AR group and 35 in the ET group $(\mathrm{p}=0.050)$. The distribution of the grade of degenerative change showed that 29 patients had osteophytes (grade I) in the AR group compared with 24 in the ET group $(p=0.957)$. Three patients in the AR group had
grade-II osteophytes with narrowing of the joint space (grade II) compared with seven in the ET group $(p=0.100)$. Four patients in the ET group had severe osteoarthritis (grade III) compared with none in the AR group ( $p=0.025)$ (Table III). Ten patients in the ET group and 22 in the AR group had normal joints $(p=0.050)$.

\section{Discussion}

The principal findings of our study were that, when compared with anatomical reconstruction, patients who underwent a tenodesis required more revision procedures and significantly more had chronic pain in the ankle, limited dorsiflexion, tenderness, instability and osteoarthritis.

The primary aim of treatment in patients with chronic anterolateral instability of the ankle is to relieve the discomfort caused by recurrent injury. Many authors have reported good short-term results after tenodesis. $5,7,11,20,31$ Rosenbaum et $\mathrm{al}^{32}$ compared the outcome after anatomical reconstruction and the Evans tenodesis in a randomised controlled trial and showed that both methods produced comparable clinical and functional outcome within one year of surgery. Kaikkonen et $\mathrm{al}^{33}$ have recently reported that ligamentous laxity usually recurs five years after the Evans tenodesis, that the range of movement of the ankle is significantly impaired, and swelling of the ankle is frequently found. A long-term patient-orientated outcome study by Barnum, Ehrlich and Zaleske ${ }^{34}$ revealed satisfactory results in $85 \%$ of 20 patients who had had an Evans tenodesis, but these results were evaluated by questionnaires and not clinically.

By contrast, most long-term clinical studies show poorer results after tenodesis. Van der Rijt and Evans ${ }^{18}$ were the first to report unsatisfactory long-term results. In their series of nine patients, who were followed for a mean of 22 years, the early, favourable results deteriorated seven to ten years after surgery. In our study, according to the rating system developed by Good et al, ${ }^{6}$ we found good to excellent results in $80 \% 15$ to 30 years after anatomical reconstruction and good to excellent results in only $33 \%$ after the Evans tenodesis.

The reason for the deterioration in functional results after tenodesis is inadequate restoration of ligamentous tension. This has been reported in both experimental and clinical studies with a long-term follow-up. ${ }^{18,22,26,27,35-38}$ A study by Karlsson et al $^{22}$ showed that persistent laxity is correlated with a poor functional result, and that anterior talar

Table III. Details of standard radiological examination (AP + lateral) in the 54 patients who had AR and the 45 who had ET

\begin{tabular}{llrrr}
\hline Grade & & AR & ET & p value \\
\hline 0 & Normal joint & 22 & 10 & 0.050 \\
I & Osteophytes without narrowing of the joint space & 29 & 24 & 0.957 \\
II & Osteophytes with narrowing of the joint space & 3 & 7 & 0.100 \\
III & $\begin{array}{l}\text { Osteophytes with total disappearance or deformation } \\
\text { of the joint space }\end{array}$ & 0 & 4 & 0.025 \\
\end{tabular}


translation is more significant than talar tilt. The recent multicentre study by Krips et $\mathrm{al}^{27}$ reported higher mean values for anterior talar translation and talar tilt on stress radiological examination two to ten years after tenodesis in comparison with anatomical reconstruction. Orava et $\mathrm{al}^{39}$ reported an incidence of almost 50\% of a radiologically evident increase in anterior talar translation two to seven years after the Evans tenodesis. In our study, we found higher mean values for anterior talar translation and talar tilt on stress radiological examination after the Evans tenodesis than after anatomical reconstruction. This can be explained by the fact that the Evans procedure reconstructs neither the anterior talofibular nor the calcaneofibular ligament, but acts on the resultant of both. The talus can therefore still sublux forward when the foot is plantar flexed.

Persistent laxity leads to recurrent inversion trauma during which repetitive shear stresses weaken the cartilage on the medial talar facet and the anteromedial rim of the medial malleolus and cause degenerative changes. ${ }^{27,30,40}$ In 1979 , Harrington ${ }^{41}$ reported osteoarthritis of the ankle in 34 patients with chronic ligamentous laxity; the degenerative changes were all on the anteromedial aspect of the joint. Karlsson et $\mathrm{al}^{22}$ found marginal osteophytes in most ankles after the Evans tenodesis and these were more numerous in those with the greatest instability. Krips et $\mathrm{al}^{27}$ found significantly more medially-located degenerative changes two to ten years after tenodesis than after anatomical reconstruction. Rosenbaum et $\mathrm{al}^{35}$ reported a high incidence of persistent long-term symptoms such as pain and a feeling of instability after the Evans tenodesis. In their study population, they found a high incidence of osteoarthritis in the anterior aspect of the ankle.

Any ligamentous reconstruction for chronic anterolateral instability of the ankle should protect the cartilage of the ankle from further damage caused by micromovement and recurrent injury. As there is more laxity after tenodesis than after anatomical reconstruction a higher incidence of osteoarthritis would be expected after tenodesis, and four patients in the ET group had severe osteoarthritis (grade III) compared with none in the AR group. A significantly larger number of patients had a revision procedure after a tenodesis than after anatomical reconstruction, most being for anterior bony impingement. Arthroscopic removal of symptomatic anterior or anteromedial osteophytes was successfully undertaken in these patients.

The lower surface of the anterior tibia and the anterior part of the medial malleolus are normally covered by articular cartilage. The anterior joint capsule attaches to the tibia above this rim of cartilage, about $5 \mathrm{~mm}$ above the joint line. It is this non-weight-bearing rim of anterior cartilage which undergoes degenerative change and is known to be damaged by inversion injuries. ${ }^{30,42}$ A repair reaction with proliferation of cartilage, the formation of scar tissue and calcification will follow. Recurrent direct (micro) trauma to this area will lead to the formation of osteophytes and more soft-tissue thickening. Tol, Verheijen and van Dijk ${ }^{43}$ concluded that the cause of pain is not the osteophyte, but impingement of hypertrophic synovial tissue between the osteophytes during dorsiflexion. Removal of the soft tissue alone may lead to symptomatic relief. The presence of talar and tibial osteophytes, however, reduces the anterior joint space. After the arthroscopic removal of soft tissue, new scar tissue will develop causing pain and limitation of dorsiflexion. The removal of the soft tissue and the bony spurs, which was successful in all our patients, is therefore recommended.

When compared with the Evans tenodesis, anatomical reconstruction leads to better functional results, more effective restoration of stability and less osteoarthritis of the ankle, even after 15 to 30 years. Anatomical reconstruction, rather than the more complex Evans tenodesis, should therefore be the primary choice of treatment in patients with chronic anterolateral instability of the ankle.

No benefits in any form have been received or will be received from a commercial party related directly or indirectly to the subject of this article.

\section{References}

1. Anderson KJ, LeCocq JF. Operative treatment of injury to the fibular collateral ligament of the ankle. J Bone Joint Surg [Am] 1954;36-A:832-52.

2. Chrisman OD, Snook GA. Reconstruction of lateral ligament tears of the ankle: an experimental study and clinical evaluation of seven patients treated by a new modification of the Elmslie procedure. $J$ Bone Joint Surg [Am] 1969;51-A:904-12.

3. Elmslie RC. Recurrent subluxation of the ankle-joint. Ann Surg 1934;100:364-7.

4. Evans DL. Recurrent dislocation of the ankle: a method of surgical treatment. Proc R Soc Med 1953;46:343-4.

5. Gillespie HS, Boucher P. Watson-Jones repair of lateral instability of the ankle. J Bone Joint Surg [Am] 1971;53-A:920-4.

6. Good CJ, Jones MA, Livingstone BN. Reconstruction of the lateral ligament of the ankle. Injury 1975;7:63-5.

7. Hedeboe J, Johannsen A. Recurrent instability of the ankle joint: surgical repair by the Watson-Jones method. Acta Orthop Scand 1979;50:337-40.

8. Hoy GA, Henderson IJP. Results of Watson-Jones ankle reconstruction for instability: the influence of articular damage. J Bone Joint Surg [Br] 1994;76-B:610-3.

9. Kjaersgaard-Andersen P, Sojbjerg JO, Wethelund JO, Helmig P, Madsen F. Watson-Jones tenodesis for ankle instability. Acta Orthop Scand 1989;60:477-80.

10. Korkala O, Tanskanen P, Mäkijärvi J, et al. Long-term results of the Evans procedure for lateral instability of the ankle. J Bone Joint Surg [Br] 1991;73-B:96-9.

11. Lucht U, Vang PS, Termansen NB. Lateral ligament reconstruction of the ankle with a modified Watson-Jones operation. Acta Orthop Scand 1981;52:363-6.

12. Ottosson L. Lateral instability of the ankle treated by a modified Evans procedure. Acta Orthop Scand 1978;49:302-5.

13. Riegler HF. Reconstruction for lateral instability of the ankle. $J$ Bone Joint Surg [Am] 1984;66-A:336-9.

14. Savastano AA, Lowe EB Jr. Ankle sprains: surgical treatment for recurrent sprains. Report of 10 patients treated with the ChrismanSnook modification of the Elmslie procedure. Am J Sports Med 1980;8:208-11.

15. Sefton GK, George J, Fitton JM, McMullen H. Reconstruction of the anterior talofibular ligament for the treatment of the unstable ankle. J Bone Joint Surg [Br] 1979;61-B:352-4. 
16. Snook GA, Chrisman OD, Wilson TC. Long-term results of the Chrisman-Snook operation for reconstruction of the lateral ligaments of the ankle. J Bone Joint Surg [Am] 1985;67-A:1-7.

17. Solheim LF, Denstad TF, Roaas A. Chronic lateral instability of the ankle: a method of reconstruction using the Achilles tendon. Acta Orthop Scand 1980;51:193-6.

18. van der Rijt AJ, Evans GA. The long-term results of Watson-Jones tenodesis. J Bone Joint Surg [Br] 1984;66-B:371-5.

19. Colton CL. Injuries of the ankle. In Wilson JN, ed. Watson-Jones fractures and joint injuries. Vol. 2. 6th edition. London: Churchill Livingstone, 1982:1104-51.

20. Younes C, Fowles JV, Fallaha M, Antoun R. Long term results of surgical reconstruction for chronic lateral instability of the ankle: comparison of Watson-Jones and Evans' techniques. J Trauma 1988;28:1330-4.

21. Peters JW, Trevino SG, Renstrom PA. Chronic lateral ankle instability. Foot Ankle 1991;12:182-91.

22. Karlsson J, Bergsten T, Lansinger O, Peterson L. Reconstruction of the lateral ligaments of the ankle for chronic lateral instability. J Bone Joint Surg [Am] 1988;70-A:581-8.

23. Sugimoto K, Takakura Y, Akiyama K, et al. Long-term results of Watson-Jones tenodesis of the ankle: clinical and radiographic findings after ten to eighteen years of follow-up. J Bone Joint Surg [Am] 1998;80-A:1587-96.

24. Broström L. Sprained ankles: VI. Surgical treatment of "chronic" ligament ruptures. Acta Chir Scand 1966;132:551-65.

25. Karlsson J, Bergsten T, Lansinger O, Peterson L. Surgical treatment of chronic lateral instability of the ankle joint: a new proedure. Am J Sports Med 1989;17:268-73.

26. Mabit C, Chaudruc JM, Fiorenza F, Huc H, Pecout C. Latera ligament of the ankle: comparative study of peroneus brevis tenodesis versus periosteal ligamentoplasty. Foot Ankle Surg 1998;4:71-6.

27. Krips R, Van Dijk CN, Halasi T, et al. Anatomical reconstruction versus tenodesis for the treatment of chronic anterolateral instability of the ankle joint: a 2- to 10-year follow-up, multicenter study. Knee Surg Sports Traumatol Arthrosc 2000;8:173-9.

28. Karlsson J, Bergsten T, Peterson L, Zachrisson BE. Radiographic evaluation of ankle joint instability. Clin J Sport Med $1991 ; 1: 166-75$

29. Lindstrand A, Mortensson W. Anterior instability in the ankle joint following acute lateral sprain. Acta Radiol 1977;18:529-39.
30. Van Dijk CN, Tol JL, Verheyen CC. A prospective study of prognostic factors concerning the outcome of arthroscopic surgery for anterior ankle impingement. Am J Sports Med 1997;25:737-45.

31. Zenni EJ, Grefer M, Krieg JK, Lambert MB, Florez R. Lateral ligamentous instability of the ankle: a method of surgical reconstruction by a modified Watson-Jones technique. Am J Sports Med 1977;5:78-83.

32. Rosenbaum D, Engelhardt M, Becker HP, Claes L, Gerngross $H$. Clinical and functional outcome after anatomic and nonanatomic ankle ligament reconstruction: Evans tenodesis versus periosteal flap. Foot Ankle Int 1999;20:636-9.

33. Kaikkonen A, Hyppänen E, Kannus P, Järvinen M. Long-term functional outcome after primary repair of the lateral ligaments of the ankle. Am J Sports Med 1997;25:150-5.

34. Barnum MJ, Ehrlich MG, Zaleske DJ. Long-term patient-oriented outcome study of a modified Evans procedure. J Pediatr Orthop 1998; 18:783-8

35. Rosenbaum D, Becker HP, Sterk J, Gerngross H, Claes L. Longterm results of the modified Evans repair for chronic ankle instability. Orthopedics 1996;19:451-5.

36. Rosenbaum D, Becker HP, Sterk J, Gerngross H, Claes L. Functional evaluation of the 10-year outcome after modified Evans repair for chronic ankle instability. Foot Ankle Int 1997;18:765-71.

37. Rosenbaum D, Becker HP, Wilke HJ, Claes LE. Tenodeses destroy the kinematic coupling of the ankle joint complex: a three-dimensional in vitro analysis of joint movement. J Bone Joint Surg $[\mathrm{Br}]$ 1998;80-B:162-8.

38. Liu SH, Baker CL. Comparison of lateral ankle ligamentous reconstruction procedures. Am J Sports Med 1993;22:313-7.

39. Orava S. Jaroma H, Weitz H, Loikkanen T, Suvela M. Radiographic instability of the ankle after Evans repair. Acta Orthop Scand 1983;54:734-8.

40. Van Dijk CN, Bossuyt PMM, Marti RK. Medial ankle pain after lateral ligament rupture. J Bone Joint Surg [Br] 1996;78-B:562-7.

41. Harrington KD. Degenerative arthritis of the ankle secondary to longstanding lateral ligament instability. J Bone Joint Surg [Am] 1979;61-A:354-61.

42. Van Dijk CN. On diagnostic strategies in patients with severe ankle sprain. Thesis, University of Amsterdam, 1994.

43. Tol JL, Verheijen CPPM, van Dijk CN. Arthroscopic treatment of anterior impingement in the ankle: a prospective study with a five- to eight-year follow-up. J Bone Joint Surg [Br] 2001;83-B:9-13. 